\title{
Computing Banhatti Indices of Hexagonal, Honeycomb and Derived Networks
}

\author{
Fazal Dayan ${ }^{1,}$, Muhammad Javaid ${ }^{1}$, Muhammad Zulqarnain ${ }^{1}$, Muhammad Tariq Ali ${ }^{2}$, \\ Bilal Ahmad ${ }^{2}$ \\ ${ }^{1}$ Department of Mathematics, University of Management and Technology, Lahore, Pakistan \\ ${ }^{2}$ Department of Mathematics and Statistics, the University of Lahore, Lahore, Pakistan \\ Email address: \\ fazaldayan1@gmail.com(F. Dayan) \\ ${ }^{*}$ Corresponding author
}

\section{To cite this article:}

Fazal Dayan, Muhammad Javaid, Muhammad Zulqarnain, Muhammad Tariq Ali, Bilal Ahmad. Computing Banhatti Indices of Hexagonal, Honeycomb and Derived Networks. American Journal of Mathematical and Computer Modelling. Vol. 3, No. 2, 2018, pp. 38-45.

doi: 10.11648/j.ajmcm.20180302.11

Received: February 13, 2018; Accepted: May 5, 2018; Published: June DD, 2018

\begin{abstract}
Banhatti indices of a graph were introduced by Kulli. In this paper we have computed the general K-Banhatti indices, first and second $\mathrm{K}-$ Banhatti indices, $\mathrm{K}$ hyper Banhatti indices, modified $\mathrm{K}$ Banhatti indices and sum connectivity Banhatti indices for hexagonal, honeycomb and honeycomb derived networks.
\end{abstract}

Keywords: Banhatti Indices, K-Banhatti Indices, K-Hyper Banhatti Indices, Modified K Banhatti Indices, Hexagonal and Honeycomb Networks

\section{Introduction}

Kulli introduced the first and second K-Banhatti indices of a graph in [1]. These are defined as,

$$
B_{1}(G)=\sum_{u e}\left[d_{G}(u)+d_{G}(e)\right], B_{2}(G)=\sum_{u e}\left[d_{G}(u) d_{G}(e)\right]
$$

where $u e$ indicate that the vertex $u$ and edge $e$ are incident in $G$. Kulli also defined some properties of these newly defined indices. The coindices of K-Banhatti indices were also defined in his work. Later kulli defined $\mathrm{K}$ hyper-Banhatti indices of V-Phenylenic nanotubes and nanotorus [2]. Gutman et al developed relations between Banhatti and Zagreb indices and discussed the lower and upper bounds for Banhatti indices of a connected graph in terms of Zagreb indices [3]. Kulli et al also computed Banhatti indices for certain families of benzenoid systems [4]. Moreover, Kulli introduced multiplicative hyper-Banhatti indices and coindices, Banhatti geometric-arithmetic index connectivity Banhatti indices for certain families of benzenoid systems [57]. The Banhatti indices were also introduced and computed by Kulli [8].

Graph theory has found considerable use in modeling chemical structures. Chemical graph theory is an important branch of mathematical chemistry that uses graph theory in the mathematical modeling of chemical phenomena ${ }^{1-3}$. Chemical graph theory has an important effect in the development of mathematical chemistry and chemical sciences.

Computing topological indices in mathematical chemistry is an important branch. Topological index has become a very useful tool in the prediction of physio chemical and pharmacological properties of a compound.

The number of vertices and edges are the topological index molecular structure matters. The main ingredients of the molecular topological models are topological indices which are the topological characterization of molecules by means of numerical invariants. These models are instrumental in the discovery of new applications of molecules with specific chemical, pharmacological and biological properties. Applications of graph theory have led to the emergence of a number of graph-theoretical indices [9]. These indices are used by various researchers in their studies. The first use of a topological index was made by the chemist Harold Wiener in 1947 [10]. In recent years many researchers have worked on computing topological indices [11-19]. Bharati, R. et al. have calculated the Zagreb, Randić, and $\mathrm{ABC}$ index of silicate, honeycomb and hexagonal networks [20].

Kulli defined atom bond connectivity reverse index of a 
molecular graph and calculated atom bond connectivity reverse index and product connectivity reverse index for oxide and honeycomb networks [21], the direct and inverse sum Banhatti indices for some graphs [22], multiplicative connectivity banhatti indices of benzenoid systems and polycyclic aromatic hydrocarbons [23] and reverse zagreb and reverse hyper-zagreb indices and their polynomials of rhombus silicate networks [24].

S. Hayat et al. [25] derived some new classes of networks from honeycomb network by using some basic graph operations like stellation, bounded dual and medial of a graph and denoted these n-dimensional honeycomb derived network of first type as $H c D N 1(n)$. We give analytic formulas of the general K-Banhatti indices, first and second $\mathrm{K}$-Banhatti indices, $\mathrm{K}$ hyper Banhatti indices, modified $\mathrm{K}$ Banhatti indices and sum connectivity Banhatti indices of the hexagonal, honeycomb and honeycomb derived networks.

\section{Calculating Banhatti Indices for the Hexagonal Network}

Triangular, square, and hexagonal are three regular plane tessellations, composed of the same kind of regular polygons. The triangular tessellation is used to define Hexagonal network and this is widely studied in [26]. A hexagonal network is shown in figure 1. There are three types of vertices based on their degree in a hexagonal network. There are only 6 vertices of degree $3,6 n-12$ vertices of degree 4 and $3 n^{2}-9 n+7$ vertices of degree 6 .

The general first and second K-Banhatti indices of a graph are defined as:

$$
\begin{array}{cc}
B_{1}{ }^{a}(G)=\sum_{u e}\left[d_{G}(u)+d_{G}(e)\right]^{a} & \text { (1) } \quad \begin{array}{c}
n, \text { the general first and second K-Banhatti indices are given } \\
\text { by }
\end{array} \\
B_{2}{ }^{a}(G)=\sum_{u e}\left[d_{G}(u) d_{G}(e)\right]^{a}, & \text { (2) } \\
B_{1}{ }^{a} H X(n)=12\left(8^{a}+9^{a}\right)+6\left(10^{a}+13^{a}\right)+12(n-3) 10^{a}+12(n-2)\left(12^{a}+14^{a}\right)+2\left(9 n^{2}-33 n+30\right) 16^{a} \\
S B_{2}{ }^{a} H X(n)=12\left(15^{a}+20^{a}\right)+6\left(21^{a}+42^{a}\right)+12(n-3) 24^{a}+12(n-2)\left(32^{a}+48^{a}\right)+2\left(9 n^{2}-33 n+30\right) 60^{a}
\end{array}
$$

where $a \in \mathbb{R}$

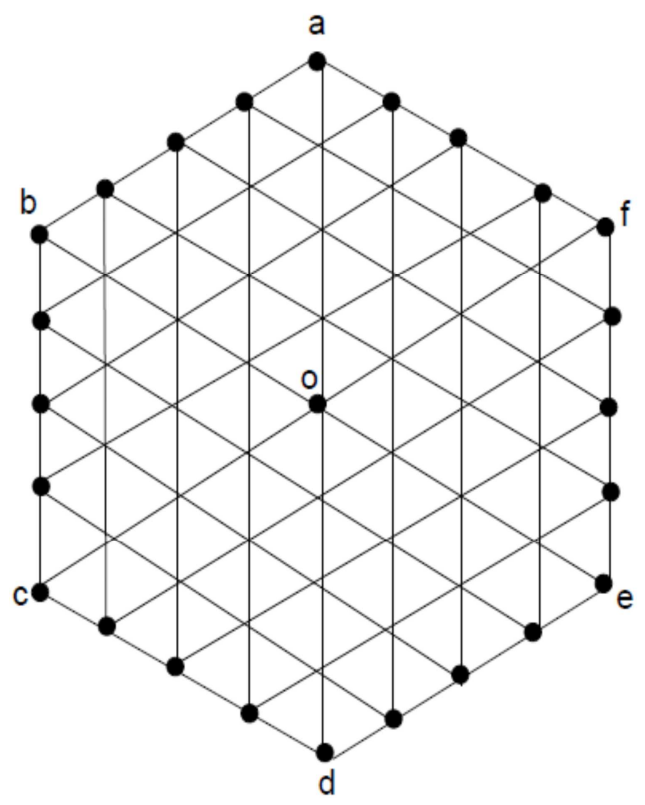

Figure 1. Hexagonal network.

Table 1. The edge degree partition of $H X(n)$ based on degree of end vertices.

\begin{tabular}{lll}
\hline $\boldsymbol{d}_{G}(\boldsymbol{u}), \boldsymbol{d}_{G}(\boldsymbol{e v})$ & $\boldsymbol{d}_{G}(\boldsymbol{e})$ & $|\boldsymbol{E}(\boldsymbol{R H O X}(\boldsymbol{n}))|$ \\
\hline$(3,4)$ & 5 & 12 \\
$(3,6)$ & 7 & 6 \\
$(4,4)$ & 6 & $6(n-3)$ \\
$(4,6)$ & 8 & $12(n-2)$ \\
$(6,6)$ & 10 & $\left(9 n^{2}-33 n+30\right)$ \\
\hline
\end{tabular}

Theorem: For a hexagonal network $H X(n)$ of dimension

Proof: Let $G$ be the graph of hexagonal network $H X(n)$ of dimension $n$, with $|V(H X(n))|=3 n^{2}-3 n+1$ and $|E(H X(n))|=9 n^{2}-15 n+6$, where $n$ is the number of vertices on one side of the hexagon. There are five type of edges based on degree of end vertices in a hexagonal network shown in table 1.

a) We compute $B_{1}{ }^{a} H C(n)$ as follows:

$$
\begin{gathered}
B_{1}{ }^{a}(H X(n))=\sum_{u e}\left[d_{G}(u)+d_{G}(e)\right]^{a} \\
=12\left(8^{a}+9^{a}\right)+6\left(10^{a}+13^{a}\right)+12(n-3) 10^{a}+12(n-2)\left(12^{a}+14^{a}\right)+\left(9 n^{2}-33 n+30\right) 16^{a}
\end{gathered}
$$

b) We compute $B_{2}{ }^{a} H C(n)$ as follows:

$$
\begin{gathered}
{B_{2}}^{a}(H X(n))=\sum_{u e}\left[d_{G}(u) d_{G}(e)\right]^{a} \\
=12\left(15^{a}+20^{a}\right)+6\left(21^{a}+42^{a}\right)+12(n-3) 24^{a}+12(n-2)\left(32^{a}+48^{a}\right)+2\left(9 n^{2}-33 n+30\right) 60^{a}
\end{gathered}
$$

Corollary: The first and second K-Banhatti indices for a hexagonal network $H X(n)$ are given by

$$
B_{1}(H X(n))=4608 n^{2}-16464 n+14718
$$




$$
B_{2}(H X(n))=64800 n^{2}-236352 n+214014
$$

Proof: Putting $a=1$ in equation (3), we get

$$
=12(17)+6(23)+120(n-3)+312(n-2)+512\left(9 n^{2}-33 n+30\right)=4608 n^{2}-16464 n+14718
$$

Putting $a=1$ in equation (4), we get

$$
=12(35)+6(63)+288(n-3)+960(n-2)+7200\left(9 n^{2}-33 n+30\right)=64800 n^{2}-236352 n+214014
$$

Corollary: The first and second K-hyper Banhatti indices for a hexagonal network $H X(n)$ are given by

$$
\begin{gathered}
H B_{1}(H X(n))=4608 n^{2}-11616 n+6954 \\
H B_{2}(H X(n))=64800 n^{2}-190752 n+136122
\end{gathered}
$$

Proof: Putting $a=2$ in equation (3), we get

$$
=1740+1614+1200 n-3600+4080(n-2)+4608 n^{2}-16896 n+15360=4608 n^{2}-11616 n+6954
$$

Putting $a=2$ in equation (4), we get

$$
\begin{gathered}
=7500+13230+6912 n-20736+39936 n-79872+64800 n^{2}-237600 n+216000 \\
=64800 n^{2}-190752 n+136122
\end{gathered}
$$

Corollary: The first and second modified K Banhatti indices for a hexagonal network $H X(n)$ are given by

$$
\begin{aligned}
& m B_{1}(H X(n))=\frac{9}{8} n^{2}-\frac{299}{8} n+\frac{361}{1092} \\
& m B_{2}(H X(n))=\frac{3}{10} n^{2}+\frac{1}{40} n+140
\end{aligned}
$$

Proof: Putting $a=-1$ in equation (3), we get

$$
=12\left(\frac{1}{8}+\frac{1}{9}\right)+6\left(\frac{1}{10}+\frac{1}{13}\right)+\frac{12}{10}(n-3)+12(n-2)\left(\frac{1}{12}+\frac{1}{14}\right)+\frac{1}{8}\left(9 n^{2}-33 n+30\right)=\frac{9}{8} n^{2}-\frac{299}{8} n+\frac{361}{1092}
$$

Putting $a=-1$ in equation (4), we get

$$
=12\left(\frac{1}{15}+\frac{1}{20}\right)+6\left(\frac{1}{21}+\frac{1}{42}\right)+\frac{1}{2}(n-3)+12(n-2)\left(\frac{1}{32}+\frac{1}{48}\right)+\frac{1}{30}\left(9 n^{2}-33 n+30\right)=\frac{3}{10} n^{2}+\frac{1}{40} n+140
$$

Corollary: The first and second sum connectivity Banhatti indices for a hexagonal network $H X(n)$ are given by

$$
\begin{gathered}
S B_{1}(H X(n))=4.5 n^{2}-6.03403029 n-9.106540386 \\
S B_{2}(H X(n))=2.323790008 n^{2}-2.217702468 n-2.390835824
\end{gathered}
$$

Proof: Putting $a=-1 / 2$ in equation (3), we get

$$
\begin{gathered}
=12\left(\frac{1}{\sqrt{8}}+\frac{1}{\sqrt{9}}\right)+6\left(\frac{1}{\sqrt{10}}+\frac{1}{\sqrt{13}}\right)+\frac{12}{\sqrt{10}}(n-3)+12(n-2)\left(\frac{1}{\sqrt{12}}+\frac{1}{\sqrt{14}}\right)+\frac{1}{2}\left(9 n^{2}-33 n+30\right) \\
=\frac{9}{2} n^{2}+\left(\frac{12}{\sqrt{10}}+\frac{12}{\sqrt{12}}+\frac{12}{\sqrt{14}}-\frac{33}{2}\right) n+4+\frac{6}{\sqrt{10}}+\frac{12}{\sqrt{13}}-\frac{12}{\sqrt{10}}-\frac{36}{\sqrt{10}}-\frac{24}{\sqrt{12}}-\frac{42}{\sqrt{14}}+15 \\
=4.5 n^{2}-6.03403029 n-9.106540386
\end{gathered}
$$

Putting $a=-1 / 2$ in equation (4), we get

$$
\begin{gathered}
=12\left(\frac{1}{\sqrt{15}}+\frac{1}{\sqrt{20}}\right)+6\left(\frac{1}{\sqrt{21}}+\frac{1}{\sqrt{42}}\right)+\frac{12}{\sqrt{24}}(n-3)+12(n-2)\left(\frac{1}{\sqrt{23}}+\frac{1}{\sqrt{48}}\right)+\frac{2}{\sqrt{60}}\left(9 n^{2}-33 n+30\right) \\
=\frac{18}{\sqrt{60}} n^{2}+\left(\frac{12}{\sqrt{24}}+\frac{12}{\sqrt{32}}+\frac{12}{\sqrt{48}}-\frac{66}{\sqrt{60}}\right) n+\frac{12}{\sqrt{20}}+\frac{6}{\sqrt{21}}+\frac{6}{\sqrt{42}}-\frac{36}{\sqrt{24}}-\frac{24}{\sqrt{32}}-\frac{24}{\sqrt{48}}+\frac{60}{\sqrt{60}} \\
=2.323790008 n^{2}-2.217702468 n-2.390835824
\end{gathered}
$$




\section{Calculating Banhatti Indices for the Honeycomb Network}

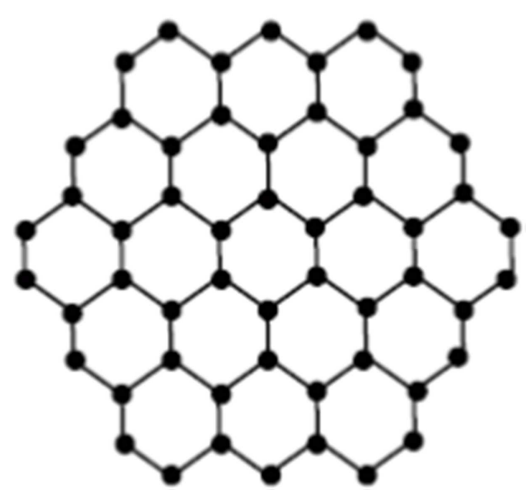

Figure 2. Honeycomb network.

A honeycomb network $H C(n)$ is obtained from $H C(n-$

1) by adding a layer of hexagons around the boundary of $H C(n-1)$, where $n$ determines the number of hexagons between the boundary and center of $H C(n)$. Honeycomb networks are used in image processing, mobile phone base stations and computer graphics. In chemistry it is used as a representation of benzenoid hydrocarbons.

A honeycomb network is shown in figure 2. There are $6 n$ vertices of degree 2 and the remaining vertices are of degree 3.

Table 2. The edge degree partition of $H C(n)$ based on degree of end vertices.

\begin{tabular}{lll}
\hline $\boldsymbol{d}_{G}(\boldsymbol{u}), \boldsymbol{d}_{G}(\boldsymbol{e v})$ & $\boldsymbol{d}_{G}(\boldsymbol{e})$ & $|\boldsymbol{E}(\boldsymbol{R H O X}(\boldsymbol{n}))|$ \\
\hline$(2,2)$ & 2 & 6 \\
$(2,3)$ & 3 & $12(n-1)$ \\
$(3,3)$ & 4 & $\left(9 n^{2}-15 n+6\right)$ \\
\hline
\end{tabular}

Theorem: For a honeycomb network $H C(n)$ of dimension $n$, the general first and second K-Banhatti indices are given by

$$
\begin{gathered}
B_{1}{ }^{a} H C(n)=12 \times 4^{a}+12(n-1)\left(5^{a}+6^{a}\right)+2\left(9 n^{2}-15 n+6\right) 7^{a} \\
B_{2}{ }^{a} H C(n)=12 \times 4^{a}+12(n-1)\left(6^{a}+9^{a}\right)+2\left(9 n^{2}-15 n+6\right) 12^{a}
\end{gathered}
$$

Proof: Let $G$ be the graph of honeycomb network $H C(n)$ of dimension $n$, with $|V(H C(n))|=6 n^{2}$ and $|E(H C(n))|=$ $9 n^{2}-3 n$. There are three types of edges based on degree of end vertices in a honeycomb network shown in table 2 .

a) We compute $B_{1}{ }^{a} H C(n)$ as follows:

$$
\begin{gathered}
B_{1}{ }^{a}(H C(n))=\sum_{u e}\left[d_{G}(u)+d_{G}(e)\right]^{a} \\
=6\left(4^{a}+4^{a}\right)+12(n-1)\left(5^{a}+6^{a}\right)+\left(9 n^{2}-15 n+6\right)\left(7^{a}+7^{a}\right) \\
=12 \times 4^{a}+12(n-1)\left(5^{a}+6^{a}\right)+2\left(9 n^{2}-15 n+6\right) 7^{a}
\end{gathered}
$$

b) We compute $B_{2}{ }^{a} H C(n)$ as follows:

$$
\begin{gathered}
B_{2}{ }^{a}(H X(n))=\sum_{u e}\left[d_{G}(u) d_{G}(e)\right]^{a} \\
=12\left(4^{a}+4^{a}\right)+12(n-1)\left(6^{a}+9^{a}\right)+\left(9 n^{2}-15 n+6\right)\left(12^{a}+12^{a}\right) \\
=12 \times 4^{a}+12(n-1)\left(6^{a}+9^{a}\right)+2\left(9 n^{2}-15 n+6\right) 12^{a}
\end{gathered}
$$

Corollary: The first and second K-Banhatti indices for a honeycomb network $H C(n)$ are given by

$$
\begin{gathered}
B_{1}(H C(n))=129 n^{2}-78 n \\
B_{2}(H C(n))=216 n^{2}-180 n+12
\end{gathered}
$$

Proof: Putting $a=1$ in equation (13), we get

$$
=48+132(n-1)+14\left(9 n^{2}-15 n+6\right)=129 n^{2}-78 n
$$

Putting $a=1$ in equation (14), we get

$$
=48+180(n-1)+24\left(9 n^{2}-15 n+6\right)=216 n^{2}-180 n+12
$$

Corollary: The first and second K-hyper Banhatti indices for a honeycomb network $H C(n)$ are given by

$$
\begin{gathered}
H B_{1}(H C(n))=882 n^{2}-738 n+48 \\
H B_{2}(H C(n))=2592 n^{2}-2916 n+516
\end{gathered}
$$

Proof: Putting $a=2$ in equation (13), we get 


$$
=192+732(n-1)+98\left(9 n^{2}-15 n+6\right)=882 n^{2}-738 n+48
$$

Putting $a=2$ in equation (14), we get

$$
=192+1404(n-1)+288\left(9 n^{2}-15 n+6\right)=2592 n^{2}-2916 n+516
$$

Corollary: The first and second modified K Banhatti indices for a honeycomb network $H C(n)$ are given by

$$
\begin{gathered}
m B_{1}(H C(n))=\frac{18}{7} n^{2}+\frac{4}{35} n+\frac{11}{35} \\
m B_{2}(H C(n))=\frac{3}{2} n^{2}+\frac{5}{6} n+\frac{2}{3}
\end{gathered}
$$

Proof: Putting $a=-1$ in equation (13), we get

$$
=3+12(n-1)\left(\frac{1}{5}+\frac{1}{6}\right)+\frac{2}{7}\left(9 n^{2}-15 n+6\right)=\frac{18}{7} n^{2}+\frac{4}{35} n+\frac{11}{35}
$$

Putting $a=-1$ in equation (14), we get

$$
=3+12(n-1)\left(\frac{1}{6}+\frac{1}{9}\right)+\frac{1}{6}\left(9 n^{2}-15 n+6\right)=\frac{3}{2} n^{2}+\frac{5}{6} n+\frac{2}{3}
$$

Corollary: The first and second sum connectivity Banhatti indices for a honeycomb network $H C(n)$ are given by

$$
\begin{aligned}
& S B_{1}(H C(n))=6.803360514 n^{2}-1.073391559 n+15.43455316 \\
& S B_{2}(H C(n))=5.196152423 n^{2}+0.2387254477 n+0.5651221296
\end{aligned}
$$

Proof: Putting $a=-1 / 2$ in equation (13), we get

$$
\begin{aligned}
& =\frac{12}{\sqrt{4}}+12(n-1)\left(\frac{1}{\sqrt{5}}+\frac{1}{\sqrt{6}}\right)+\frac{2}{\sqrt{7}}\left(9 n^{2}-15 n+6\right) \\
& =\frac{18}{\sqrt{7}} n^{2}+\left(2 \sqrt{6}+\frac{12 \sqrt{5}}{5}-\frac{30}{\sqrt{7}}\right) n+6+2 \sqrt{6}+\frac{12}{\sqrt{7}} \\
& =6.803360514 n^{2}-1.073391559 n+15.43455316
\end{aligned}
$$

Putting $a=-1 / 2$ in equation (14), we get

$$
\begin{gathered}
=\frac{12}{\sqrt{4}}+12(n-1)\left(\frac{1}{\sqrt{6}}+\frac{1}{\sqrt{9}}\right)+\frac{2}{\sqrt{12}}\left(9 n^{2}-15 n+6\right) \\
=\frac{18}{\sqrt{12}} n^{2}+\left(\frac{12}{\sqrt{6}}+4-\frac{30}{\sqrt{12}}\right) n+2-\frac{12}{\sqrt{6}}+\frac{12}{\sqrt{12}} \\
=5.196152423 n^{2}+0.2387254477 n+0.5651221296
\end{gathered}
$$

\section{Calculating Banhatti Indices for the Honeycomb Derived Networks}

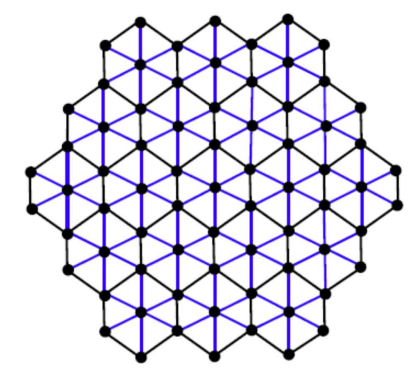

In figure 3 a honeycomb derived network $\operatorname{HcDN1}(n)$ with dimension 3 is given, where the black colored graph is 3dimensional honeycomb network and blue colored graph is its stellation. Now we compute the general K-Banhatti indices, first and second $\mathrm{K}$-Banhatti indices, $\mathrm{K}$ hyper Banhatti indices, modified $\mathrm{K}$ Banhatti indices and sum connectivity Banhatti indices of the honeycomb derived networks. First, we compute these indices for honeycomb derived network of first type, $\operatorname{HcDN1}(n)$ in the following theorem.

Theorem: For a honeycomb derived network $\operatorname{HcDN1}(n)$, the general first and second K-Banhatti indices are given by

Figure 3. Honeycomb derived network HcDn1 with dimension 3. 
$B_{1}{ }^{a}(\operatorname{HcDN} 1(n))=12 \times 7^{a}+12\left(n-{ }^{-1}\right)\left(9^{a}+11^{a}\right)+6 n\left(10^{a}+13^{a}\right)+18(n-1)\left(14^{a}+15^{a}\right)+2\left(27 n^{2}-57 n+130\right) \times 16^{a}$
$B_{2}{ }^{a}(\operatorname{HcDN} 1(n))=12 \times 12^{a}+12\left(n-{ }^{`} 1\right)\left(18^{a}+30^{a}\right)+6 n\left(21^{a}+42^{a}\right)+18(n-1)\left(45^{a}+54^{a}\right)+2\left(27 n^{2}-57 n+130\right) \times 60^{a}$

Proof: We compute the required results as follows:

(i) To compute $B_{1}{ }^{a}(\operatorname{HcDN1}(n))$,

$$
\begin{gathered}
=12\left(7^{a}+7^{a}\right)+12\left(n-{ }^{`} 1\right)\left(9^{a}+11^{a}\right)+6 n\left(10^{a}+13^{a}\right)+18(n-1)\left(14^{a}+15^{a}\right)+\left(27 n^{2}-57 n+130\right)\left(16^{a}+16^{a}\right) \\
=12 \times 7^{a}+12\left(n-{ }^{`} 1\right)\left(9^{a}+11^{a}\right)+6 n\left(10^{a}+13^{a}\right)+18(n-1)\left(14^{a}+15^{a}\right)+2\left(27 n^{2}-57 n+130\right) \times 16^{a}
\end{gathered}
$$

(ii) To compute $B_{2}{ }^{a}(H c D N 1(n))$,

$$
\begin{aligned}
& =6\left(12^{a}+12^{a}\right)+12(n-` 1)\left(18^{a}+30^{a}\right)+6 n\left(21^{a}+42^{a}\right)+18(n-1)\left(45^{a}+54^{a}\right)+\left(27 n^{2}-57 n+130\right)\left(60^{a}+60^{a}\right) \\
= & 12 \times 12^{a}+12(n-` 1)\left(18^{a}+30^{a}\right)+6 n\left(21^{a}+42^{a}\right)+18(n-1)\left(45^{a}+54^{a}\right)+2\left(27 n^{2}-57 n+130\right) \times 60^{a}
\end{aligned}
$$

Corollary: The first and second K-Banhatti indices for a honeycomb derived network HcDN1(n) are given by

$$
\begin{gathered}
B_{1}(\operatorname{HcDN} 1(n))=864 n^{2}-924 n+282 \\
B_{2}(H c D N 1(n))=3240 n^{2}-4104 n+1386
\end{gathered}
$$

Proof: Putting $a=1$ in equation (23), we get

$$
\begin{gathered}
=12 \times 7+12(n-` 1)(9+11)+6 n(10+13)+18(n-1)(14+15)+2\left(27 n^{2}-57 n+130\right) \times 16 \\
=864 n^{2}-924 n+282
\end{gathered}
$$

Putting $a=1$ in equation (24), we get

$$
\begin{gathered}
=12 \times 12+12(n-` 1)(18+30)+6 n(21+42)+18(n-1)(45+54)+2\left(27 n^{2}-57 n+130\right) \times 60 \\
=3240 n^{2}-4104 n+1386
\end{gathered}
$$

Corollary: The first and second K-hyper Banhatti indices for a honeycomb derived network $H c D N 1(n)$ are given by

$$
\begin{gathered}
H B_{1}(H c D N 1(n))=1382 n^{2}-17586 n+5946 \\
H B_{2}(H c D N 1(n))=194400 n^{2}-293544 n+114102
\end{gathered}
$$

Proof: Putting $a=2$ in equation (23), we get

$$
\begin{gathered}
=12 \times 49+12(n-` 1)(81+121)+6 n(100+169)+18(n-1)(196+225)+2\left(27 n^{2}-57 n+130\right) \times 256 \\
=1382 n^{2}-17586 n+5946
\end{gathered}
$$

Putting $a=2$ in equation (24), we get

$$
\begin{aligned}
=12 \times 144+12(n-` 1)\left(18^{2}+30^{2}\right) & +6 n\left(21^{2}+42^{2}\right)+18(n-1)\left(45^{2}+54^{2}\right)+2\left(27 n^{2}-57 n+130\right) \times 60^{2} \\
& =194400 n^{2}-293544 n+114102
\end{aligned}
$$

Corollary: The first and second modified K Banhatti indices for a honeycomb derived network $\operatorname{HcDN1}(n)$ are given by

$$
\begin{gathered}
m B_{1}(H c D N 1(n))=3.375 n^{2}-1.153504829 n+13.054329 \\
m B_{2}(H c D N 1(n))=\frac{9}{10} n^{2}+\frac{23}{70} n+\frac{1}{5}
\end{gathered}
$$

Proof: Putting $a=-1$ in equation (23), we get

$$
\begin{gathered}
=\frac{12}{7}+12(n-` 1)\left(\frac{1}{9}+\frac{1}{11}\right)+6 n\left(\frac{1}{10}+\frac{1}{13}\right)+18(n-1)\left(\frac{1}{14}+\frac{1}{15}\right)+\frac{2}{16}\left(27 n^{2}-57 n+130\right) \\
=3.375 n^{2}-1.153504829 n+13.054329
\end{gathered}
$$

Putting $a=-1$ in equation (24), we get 


$$
\begin{gathered}
=\frac{12}{12}+12(n-1)\left(\frac{1}{18}+\frac{1}{30}\right)+6 n\left(\frac{1}{21}+\frac{1}{42}\right)+18(n-1)\left(\frac{1}{45}+\frac{1}{54}\right)+\frac{2}{60}\left(27 n^{2}-57 n+130\right) \\
=\frac{9}{10} n^{2}+\frac{23}{70} n+\frac{1}{5}
\end{gathered}
$$
by

Corollary: The first and second sum connectivity Banhatti indices for a honeycomb derived network $\operatorname{HcDN1}(n)$ are given

$$
\begin{gathered}
S B_{1}(\operatorname{HcDN1}(n))=13.5 n^{2}-1.86211431 n+52.45915517 \\
S B_{2}(H c D N 1(n))=6.971370023 n^{2}-2.33012604 n+26.87786861
\end{gathered}
$$

Proof: Putting $a=-1 / 2$ in equation (23), we get

$$
\begin{aligned}
=\frac{12}{\sqrt{7}}+12(n-` 1)\left(\frac{1}{\sqrt{9}}+\frac{1}{\sqrt{11}}\right) & +6 n\left(\frac{1}{\sqrt{10}}+\frac{1}{\sqrt{13}}\right)+18(n-1)\left(\frac{1}{\sqrt{14}}+\frac{1}{\sqrt{15}}\right)+\frac{2}{\sqrt{16}}\left(27 n^{2}-57 n+130\right) \\
& =13.5 n^{2}-1.86211431 n+52.45915517
\end{aligned}
$$

Putting $a=-1 / 2$ in equation (24), we get

$$
\begin{gathered}
=\frac{12}{\sqrt{12}}+12(n-` 1)\left(\frac{1}{\sqrt{18}}+\frac{1}{\sqrt{30}}\right)+6 n\left(\frac{1}{\sqrt{21}}+\frac{1}{\sqrt{42}}\right)+18(n-1)\left(\frac{1}{\sqrt{45}}+\frac{1}{\sqrt{54}}\right)+\frac{2}{\sqrt{60}}\left(27 n^{2}-57 n+130\right) \\
=6.971370023 n^{2}-2.33012604 n+26.87786861
\end{gathered}
$$

\section{Conclusion}

In this paper hexagonal, honeycomb and honeycomb derived network $\operatorname{HcDN1}(n)$ are studied and the analytical closed formulas are determined for the general K-Banhatti indices, first and second $\mathrm{K}$-Banhatti indices, $\mathrm{K}$ hyper Banhatti indices, modified $\mathrm{K}$ Banhatti indices and sum connectivity Banhatti indices of hexagonal, honeycomb and honeycomb derived network $\operatorname{HcDN1}(n)$. It will help to understand the physical features, chemical reactivities and biological activities of the hexagonal and honeycomb and honeycomb derived network $H c D N 1(n)$. These results can provide a significant determination in the pharmaceutical industry.

\section{Acknowledgements}

The authors would like to express their sincere gratitude to the anonymous referees for their insightful comments and valuable suggestions, which led to a number of improvements in the earlier version of this manuscript.

\section{References}

[1] V. R. Kulli, K-Banhatti indices of graphs, Journal of Computer and Mathematical Sciences, 7(4), 213-218, 2016.

[2] V. R. Kulli, On K Banhatti indices and K hyper-Banhatti indices of V-Phenylenic nanotubes and nanotorus, Journal of Computer and Mathematical Sciences, 7(6), 302-307, 2016.

[3] Gutman, V. R. Kulli, B. Chaluvaraju and H. S. Baregowda, On Banhatti and Zagreb indices, Journal of the International Mathematical Virtual Institute, 7, 53-67, 2017.
[4] V. R. Kulli, B. Chaluvaraju and H. S. Boregowda, Connectivity Banhatti indices for certain families of benzenoid systems, Journal of Ultra Chemistry, 13(4), 81-87, 2017.

[5] V. R. Kulli, Multiplicative hyper-Banhatti indices and coindices of graphs, International Journal of Mathematical Archive, 7(6), 60-65, 2016.

[6] V. R. Kulli, A new Banhatti geometric-arithmetic index, International Journal of Mathematical Archive, 8(4), 112-115, 2017.

[7] V. R. Kulli, B. Chaluvaraju and H. S. Boregowda, Connectivity Banhatti indices for certain families of benzenoid systems, Journal of Ultra Chemistry, 13(4), 81-87, 2017.

[8] V. R. Kulli Computing Banhatti Indices of Networks, International Journal of Advances in Mathematics Volume 2018, Number 1, 31-40, 2018.

[9] Mehdi Alaeiyan, Amir Bahrami, Javad Yazdani, Schultz Index of Nanoporous, Australian Journal of Basic and Applied Sciences, 5(6), 250 - 252, 2011.

[10] Wiener, H. Structural determination of paraffin boiling points. J. Am. Chem. Soc. 1947, 69, 17-20.

[11] Gutman, I. Degree-Based topological indices. Croat. Chem. Acta, 86, 315-361, 2013.

[12] Garcia, I.; Fall, Y.; Gomez, G. Using topological indices to predict anti-alzheimer and antiparasitic GSK-3 inhibitors by multi-target QSAR in silico screening. Molecules 15, 54085422,2010

[13] Furtula, B.; Gutman, I.; Dehmer, M. On structure-sensitivity of degree based topological indices. Appl. Math. Comput., 219, 8973-8978, 2013. 
[14] Hao, J. Theorems about Zagreb Indices and Modified Zagreb Indices. MATCH Commun. Math. Comput. Chem, 65, 659670, 2011.

[15] Xu, K.; Liu, M.; Das, K. C.; Gutman, I.; Furtula, B. A survey on graphs extremal with respect to distance-based topological indices. MATCH Commun. Math. Comput. Chem., 71, 461508, 2014.

[16] Klavzar, S.; Deutsch, E. M-Polynomial and Degree-Based Topological Indices. Iran. J. Math. Chem., 6, 93-102, 2015.

[17] Dobrynin, A. A.; Entringer, R.; Gutman, I. Wiener index of trees: Theory and applications. Acta Appl. Math., 66, 211249, 2001.

[18] Kier, L. B.; Hall, L. H. Molecular Connectivity in StructureActivity Analysis; John Wiley \& Sons: New York, NY, USA, 1986.

[19] Zhong, L.: The harmonic index for graphs. Appl. Math. Lett., 25, 561-566, 2012.

[20] Bharati Rajan, Albert William, Cyriac Grigorious and Sudeep Stephen, On Certain Topological Indices of Silicate, Honeycomb and Hexagonal Networks, J. Comp. \& Math. Sci. $3(5), 530-535,2012$.
[21] [21]V. R. Kulli,, Atom bond connectivity reverse and product connectivity reverse indices of oxide and honeycomb networks, Intern. J. Fuzzy Mathematical Archive, 15(1), 1-5, 2018.

[22] [22]V. R. Kulli, Direct and inverse sum Banhatti indices, International Research Journal of Pure Algebra-7(9), 823-827, 2017.

[23] V. R. Kulli, Multiplicative connectivity banhatti indices of benzenoid systems and polycyclic aromatic hydrocarbons, Journal of Computer and Mathematical Sciences, 9(3), 212$220,2018$.

[24] V. R. Kulli, Reverse zagreb and reverse hyper-zagreb indices and their polynomials of rhombus silicate networks, Annals of Pure and Applied Mathematics, 16(1), 47-51, 2018.

[25] Sakander Hayat, Mehar Ali Malik and Muhammad Imran, Computing topological indices of honeycomb derived networks, Romanian journal of information science and technology, Volume 18, Number 2, 144-165, 2015.

[26] M. S. Chen, K. G. Shin, D. D. Kandlur, “Addressing, routing, and broadcasting in hexagonal mesh multiprocessors", IEEE Transactions on Computers 39, 10-18, 1990. 